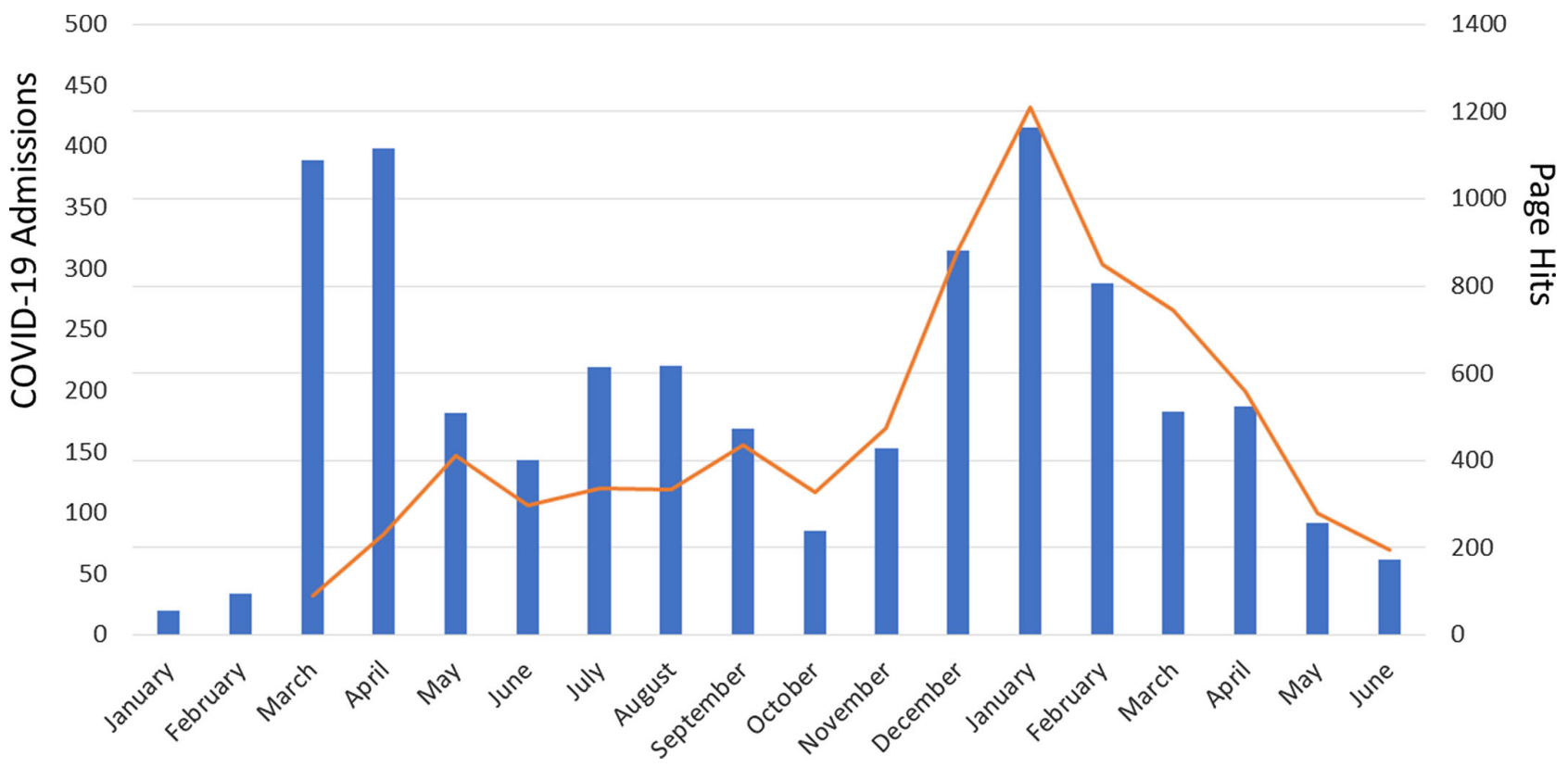

Fig. 1. COVID-19 guidelines page views (bars) compared to inpatient COVID-19 admissions (line graph), January 2020 through June 2021.

\section{References}

1. Helou RI, Foudraine DE, Catho G, Peyravi Latif A, Verkaik NJ, Verbon A. Use of stewardship smartphone applications by physicians and prescribing of antimicrobials in hospitals: a systematic review. PLoS One 2020;15:1-14.

2. Davalbhakta S, Advani S, Kumar S, et al. A systematic review of smartphone applications available for coronavirus disease 2019 (COVID19) and the assessment of their quality using the Mobile Application Rating Scale (MARS). J Med Syst 2020;44:164.
3. Nori P, Patel PK, Stevens MP. Pandemic stewardship: Reflecting on new roles and contributions of antimicrobial stewardship programs during COVID-19. Infect Control Hosp Epidemiol 2021. doi:10.1017/ ice.2021.172.

4. Nestler MJ, Godbout E, Lee K, et al. Impact of COVID-19 on pneumoniafocused antibiotic use at an academic medical center. Infect Control Hosp Epidemiol 2021;42:915-916.

\title{
Severe acute respiratory coronavirus virus 2 (SARS-CoV-2) seroprevalence among laboratory staff: Safe handling of coronavirus disease 2019 (COVID-19) samples
}

\author{
Cedric Hartard PharmD, $\mathrm{PhD}^{1,2}$, Nelly Agrinier MD, $\mathrm{PhD}^{3,4}$, Patricia Franck PharmD ${ }^{5}$, Christine Prin-Mathieu PhD ${ }^{6}$, \\ Anne Debourgogne PharmD, $\mathrm{PhD}^{6}$, Veronique Venard PharmD, $\mathrm{PhD}^{1}$, Evelyne Schvoerer MD, $\mathrm{PhD}^{1,2}$ and Hélène Jeulin \\ PharmD, PhD ${ }^{1,2}$ (1) \\ ${ }^{1}$ Laboratoire de Virologie, Centre Hospitalier Régional Universitaire-Nancy, Nancy, France, ${ }^{2}$ Laboratoire de Chimie Physique et Microbiologie pour \\ l'Environnement (CNRS) pour les Matériaux et l'Environnement Unité Mixte de Recherche (LCPME), Université de Lorraine, Nancy, France, ${ }^{3} E$ pidémiologie \\ Clinique du Centre d'Investigation Clinique, Centre Hospitalier Régional Universitaire-Nancy, Institut national de la santé et de la recherche médicale (INSERM), \\ Université de Lorraine, Nancy, France, ${ }^{4}$ Adaptation, mesure et évaluation en santé (APEMAC), Université de Lorraine, Nancy, France, ${ }^{5}$ Pôle Laboratoire, Centre \\ Hospitalier Régional Universitaire-Nancy, Nancy, France and ${ }^{6}$ Plateau technique automatisé, Centre Hospitalier Régional Universitaire-Nancy, Nancy, France
}

To the Editor-Since the beginning of the coronavirus disease 2019 (COVID-19) epidemic in France in March 2020, laboratories have had to reorganize to implement COVID-19 diagnosis at a large

Author for correspondence: Hélène Jeulin, E-mail: h.jeulin@chru-nancy.fr Cite this article: Hartard C, et al. (2022). Severe acute respiratory coronavirus virus 2 (SARS-CoV-2) seroprevalence among laboratory staff: Safe handling of coronavirus disease 2019 (COVID-19) samples. Infection Control \& Hospital Epidemiology, 43: 1738-1740, https://doi.org/10.1017/ice.2021.334 scale. In this context, the handling of samples from suspected COVID-19 patients can expose laboratory staff to severe acute respiratory coronavirus virus 2 (SARS-CoV-2). The protection of healthcare workers (HCWs) is a critical point for pandemic control, at an individual level for care continuity and at a collective scale to avoid transmission to their contact cases. ${ }^{1}$ Guidelines for respiratory- or stool-sample handling have recommended wearing filtering facepiece respirator 2 (FFP-2) mask, double pairs 
of gloves, and a disposable gown. After the first pretreatment in a microbiological safety station, samples need further biological inactivation before viral RNA extraction and genome amplification for SARS-CoV-2 detection.

In our laboratory, the number of SARS-CoV-2 RT-PCR tests increased gradually, from 20 analyses per day in February 2020 to 1,500 per day by the end of April 2020. The staff from the molecular microbiology department was the first to be involved. Later, additional technicians had to reinforce the team and a large proportion of laboratory technicians were involved in handling SARS-CoV-2 samples. At the time of the study, 9,727 samples had been processed in the laboratory, among which 3,182 were positive for SARS-CoV-2 (32.7\%).

In April 2020, a screening campaign was proposed to the whole laboratory staff of the Nancy University Hospital to determine their anti-SARS-CoV-2 serological status. All eligible laboratory workers were asked to complete a questionnaire. The following clinical and epidemiological data were collected: year of birth, sex, department within the laboratory (ie, hematology, microbiology, reproductive biology, human leukocyte antigen typing, immunology, molecular microbiology, cytometry, emergency analyses, reception and dispatching, automated analyses, genetic, pharmacology, biochemistry, point-of-care supervision, information technology support, management, environmental biology, biopathology, cleaning, and hemophilia center), and exposure to sample triple packaging or to respiratory and stool samples, exposure to a confirmed or suspected COVID-19 case (in a professional or personal context). Data regarding COVID-19-linked symptoms (ie, flu-like syndrome, dry cough, digestive disorders, loss of taste and smell) were also collected.

The detection of anti-SARS-CoV-2 IgM and IgG was performed using a flow lateral immunoassay (Biosynex BSS IgM/ IgG, Biosynex Swiss Illkirch-Graffenstaden, France). Staff with positive serology and without a prior COVID-19 diagnosis were recommended for RT-PCR in nasopharyngeal swab and further serological follow-up.

The association between exposure to sample triple packaging, exposure to respiratory or stool samples collected to detect SARS-CoV-2, symptoms attributable to COVID-19, and SARSCoV-2 seroprevalence were tested using the $\chi^{2}$ test or the Fisher exact test, according to condition of use. $P$ values were two-tailed, and the significance level was set at .05 . We used SAS version 9.4 statistical software (SAS Institute, Cary, NC) to conduct the analyses.

Among 417 laboratory workers, 396 were eligible for the study. Most workers were women $(81.1 \%)$. The median age was 42.5 years (range, 20-68). In total, 178 laboratory workers (44.9\%) had been in contact with COVID-19 samples packaging, while 147 (37.1\%) had been in contact with stool and/or respiratory samples (Table 1). For the management of the pandemic, 35 (8.8\%) laboratory workers were specifically involved in the COVID-19 diagnosis sector. Overall, 135 (34.1\%) and $109(27.5 \%)$ workers had been in contact with a confirmed or suspected COVID-19 case, respectively.

SARS-CoV-2 antibodies were detected in 9 laboratory workers (seroprevalence, 2.3\%). The most exposed persons were maintenance agents, microbiology technicians, and COVID-19 area staff, but the laboratory department was not associated with SARS-CoV-2 seroprevalence $(P=.54)$. Likewise, handling COVID-19 sample packaging $(P=.74)$ or handling samples from confirmed or suspected COVID-19 patients $(P=.30)$ were not associated with SARS-CoV-2 seroprevalence.
Table 1. Characteristics of the Laboratory Staff Cohort

\begin{tabular}{|c|c|c|}
\hline Cohort Description & No. & $\%$ or Mean \\
\hline Age & 396 & $42.5 y$ \\
\hline \multicolumn{3}{|l|}{ Sex } \\
\hline Male & 75 & 18.9 \\
\hline Female & 321 & 81.1 \\
\hline \multicolumn{3}{|c|}{ Contact with COVID-19 sample packaging } \\
\hline Yes & 178 & 44.9 \\
\hline No & 218 & 55.1 \\
\hline \multicolumn{3}{|c|}{ Contact with COVID-19 sample } \\
\hline Yes & 147 & 37.1 \\
\hline No & 249 & 62.9 \\
\hline \multicolumn{3}{|c|}{ Previous COVID-19 diagnosis (RT-PCR) } \\
\hline No & 370 & 93.4 \\
\hline Yes & 26 & 6.6 \\
\hline \multicolumn{3}{|l|}{ SARS-CoV-2 RT-PCR } \\
\hline Positive & 6 & 22.2 \\
\hline Negative & 21 & 77.8 \\
\hline \multicolumn{3}{|c|}{ Contact with a confirmed COVID-19 case } \\
\hline Yes & 109 & 27.5 \\
\hline No & 287 & 72.5 \\
\hline \multicolumn{3}{|c|}{ Contact with a suspected-COVID-19 case } \\
\hline Yes & 135 & 34.1 \\
\hline No & 261 & 65.9 \\
\hline \multicolumn{3}{|l|}{ Fever } \\
\hline Yes & 78 & 19.7 \\
\hline No & 318 & 80.3 \\
\hline \multicolumn{3}{|l|}{ Cough } \\
\hline Yes & 88 & 22.2 \\
\hline No & 308 & 77.8 \\
\hline \multicolumn{3}{|c|}{ Gastro-intestinal symptoms } \\
\hline Yes & 63 & 15.9 \\
\hline No & 333 & 84.1 \\
\hline \multicolumn{3}{|l|}{ Anosmia/Ageusia } \\
\hline Yes & 11 & 2.8 \\
\hline No & 384 & 97.2 \\
\hline \multicolumn{3}{|c|}{ Anti-SARS-CoV-2 IgM/IgG } \\
\hline Yes & 9 & 2.3 \\
\hline No & 387 & 97.7 \\
\hline
\end{tabular}

Note. RT-PCR, reverse-transcription polymerase chain reaction.

The laboratory workers had a median age of 42.5 years (range, 20-68), and most were women. A large study on HCWs did not show any association between age or sex with positivity for SARS-CoV-2 IgG. ${ }^{2}$ Interestingly, sex differences were observed in the perception of epidemic, with women being more emotionally affected and giving more attention to protective measures. ${ }^{3}$

Many studies have evaluated SARS-CoV-2 seroprevalence in the general population and hospital HCWs, but to our knowledge, no studies have focused on laboratory staff. In HCWs, the 
seroprevalence was higher, reaching $8.5 \%$ in Geneva University Hospital employees ${ }^{4}$ and $13.35 \%$ in a COVID-19-dedicated hospital in India. ${ }^{5}$ In these studies, the proportion of anti-SARSCoV-2 seroconversion was higher in employees working in COVID-19 areas. Risk factors included nosocomial outbreak and the use of public transportation. ${ }^{4}$ This last point was not evaluated in our study, but other nonprofessional risk factors, such as a contact with COVID-19 confirmed case, were not associated with a seroconversion.

In the urban area of the hospital around the same date, the raw SARS-CoV-2 seroprevalence was $2.1 \%$ among 2,006 individuals, ${ }^{6}$ suggesting the absence of high risk among laboratory staff, probably due to the strict application of the recommendations of the French Society of Microbiology (SFM) concerning sample handling. The benefit of correct use of personal protective equipment was also observed in HCWs, even in the most exposed groups. ${ }^{7}$

Despite the small size of the cohort and of self-reporting data collection, the work presented here originally targets SARSCoV-2-exposed laboratory staff. Today, most staff have been vaccinated, and studies evaluating the exposure of laboratory workers to a new airborne and/or hand-borne pathogen will no longer be possible. These data confirm the effectiveness of the good laboratory practices, which have to be quickly applied in future viral emergencies.

Acknowledgments. We thank all the laboratory staff who accepted to contribute to the study. We particularly thank the laboratory management staff, health executives, the staff of the Centre Regional de Traitement de l'Hemophilie and Dr Birgit Frotscher, and the young biologists that participated to sampling.
Financial support. No financial support was provided relevant to this article.

Conflicts of interest. All authors report no conflicts of interest relevant to this article.

\section{References}

1. Kea B, Johnson A, Lin A, et al. An international survey of healthcare workers use of personal protective equipment during the early stages of the COVID-19 pandemic. J Am Coll Emerg Physicians Open 2021;2:1-10.

2. Kasztelewicz B, Janiszewska K, Burzyńska J, Szydłowska E, Migdał M, Dzierżanowska-Fangrat $\mathrm{K}$. Prevalence of IgG antibodies against SARSCoV-2 among healthcare workers in a tertiary pediatric hospital in Poland. PLoS One. 2021;16:1-11.

3. Huang Q, Luo LS, Wang YY, Jin YH, Zeng XT. Gender differences in psychological and behavioral responses of infected and uninfected healthcare workers during the early COVID-19 outbreak. Front Public Heal 2021;9:1-8.

4. Martischang R, Iten A, Arm I, et al. SARS-CoV-2 seroconversion and occupational exposure of employees at a Swiss university hospital: a large longitudinal cohort study. Infect Control Hosp Epidemiol 2021;2:1-8.

5. Mahto M, Banerjee A, Biswas B, Kumar S, Agarwal N, Singh PK. Seroprevalence of IgG against SARS-CoV-2 and its determinants among healthcare workers of a COVID-19 dedicated hospital of India. Am J Blood Res 2021;11:44-52.

6. Gégout Petit A, Jeulin H, Legrand K, et al. Seroprevalence of SARS-CoV-2, symptom profiles and sero-neutralization in a suburban Area, France. Viruses. 2021;13:1076.

7. Caselli D, Loconsole D, Dario R, Chironna M, Aricò M. Effectiveness of preventive measures in keeping low prevalence of SARS-CoV-2 infection in healthcare workers in a referral children's hospital in southern Italy. Pediatr Rep 2021;13:118-124.

\title{
Healthcare-associated transmission of severe acute respiratory coronavirus virus 2 (SARS-CoV-2) among Thai healthcare personnel who receive 2 doses of a coronavirus disease 2019 (COVID-19) vaccine: A call for considering a booster dose
}

\author{
Anucha Apisarnthanarak MD , Sira Nantapisal MD, $\mathrm{PhD}^{2}$, Thanus Pienthong $\mathrm{MD}^{1}$, Piyaporn Apisarnthanarak $\mathrm{MD}^{3}$ and \\ David J. Weber MD, MPH \\ ${ }^{1}$ Division of Infectious Diseases, Department of Medicine, Thammasat University Hospital, Pathum Thani, Thailand, ${ }^{2}$ Division of Immunology, Department of \\ Pediatrics, Thammasat University Hospital, Pathum Thani, Thailand, ${ }^{3}$ Department of Radiology, Siriraj Hospital, Bangkok, Thailand and ${ }^{4}$ Gillings School of Global \\ Public Health, Chapel Hill, North Carolina, United States
}

To the Editor-There have been consistent reports of healthcare personnel (HCP) acquiring COVID-19 as a result of workplace exposure, either directly or indirectly. ${ }^{1,2}$ In Thailand, the emerging alpha variant of severe acute respiratory coronavirus virus 2 (SARS-CoV-2) replaced the original strain in February 2021, followed by the emergence of the delta variant of SARS-CoV-2 in

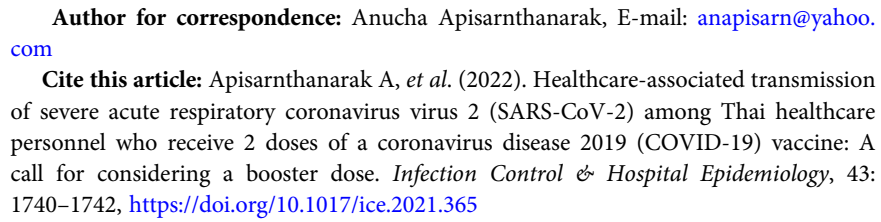

Cite this article: Apisarnthanarak A, et al. (2022). Healthcare-associated transmission of severe acute respiratory coronavirus virus 2 (SARS-CoV-2) among Thai healthcare personnel who receive 2 doses of a coronavirus disease 2019 (COVID-19) vaccine: A call for considering a booster dose. Infection Control \& Hospital Epidemiology, 43: 1740-1742, https://doi.org/10.1017/ice.2021.365

April 2021. ${ }^{3}$ Immunization of HCP was the first priority of the coronavirus disease 2019 (COVID-19) vaccination campaign, and most $\mathrm{HCP}$ received vaccine, based on the government vaccine allocation. As of July 19, 2021, CoronaVac (Sinovac-Biotech) and ChAdOx-1 (AstraZeneca) are the only 2 COVID-19 vaccines available in Thailand. Despite 2 doses of vaccine, the number of HCP who were infected with SARS-CoV-2 in Thailand is continuously increasing. To better understand the epidemiology of healthcare-associated SARS-CoV-2 transmission among HCP, we performed a retrospective review of HCP who received 2 doses of COVID-19 vaccine.

At Thammasat University Hospital a 650-bed, academic medical center in Pratum Thani, Thailand, a COVID-19 